\title{
Developing research expertise in applied linguistics
}

\section{Capacity-building for today's interdisciplinary challenges ${ }^{*}$}

\author{
Alison Wray and Mike Wallace \\ Cardiff University, UK
}

This paper explores the ambiguous nature of applied linguistics as a field of enquiry, to contextualise the interpretation of data from an empirical study into how research expertise in applied linguistics is conceptualised, and how it develops during an academic's career. Key findings from the study include the importance of being willing to work at the boundaries of one's knowledge, the capacity to communicate one's ideas effectively, and the role of a good quality research environment for developing knowledge, skills and confidence. It is proposed that these features fit well with the modern imperative of addressing the world's major problems though a cross-disciplinary approach to research, putting applied linguists into a strong position to contribute to new research knowledge.

Keywords: research expertise, applied linguistics, interdisciplinarity, capacity building

\section{Expertise in what? Applied linguistics as an ambiguous field of enquiry}

Researchers operate in an increasingly competitive environment, yet one with many opportunities for those able to direct their knowledge and skills appropriately. This

\footnotetext{
* We thank the 31 social scientist informants in our study, and the others, including several applied linguists, with whom we had less formal conversations or interviews that enriched our understanding of how research expertise is perceived. The paper has benefited from many conversations with colleagues, and from helpful feedback on an earlier draft from Alison J Mackey. The research reported here was funded by the UK Economic and Social Research Council (ESRC) as part of the Researcher Development Initiative. The project, "Enhancing expert thinking and problem-solving: the development of insight and perspective in theory and practice" ran at Cardiff University from August 2010 to January 2014, Grant reference RES-046-25-0021. The ideas expressed in this paper are those of the authors and do not represent the views of the ESRC.
} 
paper addresses some important questions regarding the future of applied linguistics in this context: What are the characteristics of research expertise in applied linguistics and how are they acquired? What kinds of specialist knowledge and skills are most relevant? How are applied linguists placed for making a distinctive and valuable contribution in a world that is increasingly focussed on cross-disciplinary approaches to addressing major social challenges? And how can applied linguists be most effectively supported in acquiring the research expertise needed to participate in these investigations?

Answers to these questions have important implications for how departments of applied linguistics, and the national and international associations of applied linguistic researchers, develop policy and practice in the future. Yet it is far from self-evident that the applied linguistics community has a clear sense of how it might optimise its contribution to cutting edge research.

As an exploratory contribution, we will first reflect on the characteristics of applied linguistics as a field of enquiry, ${ }^{1}$ since, as we shall argue, they influence how applied linguists operate and perceive themselves. Second, we will draw on an empirical study of the nature and development of research expertise in applied linguistics, to offer some pointers of potential value to today's early and mid-career researchers and to those with responsibility for overseeing their professional development. The following research questions framed our enquiry:

- Who decides who are the leading researchers, and on what basis?

- What are the characteristics of current leading researchers, and of the work they do?

- How are the knowledge and skills in field-leading applied linguistic work developed?

- How were those who have acquired research expertise supported in developing it, and how do they now support the up-coming generation of less-experienced researchers?

Third, in the light of our findings, we will suggest some future directions for the applied linguistics community.

A widely acknowledged characteristic of applied linguistics is an apparently intractable ambiguity over what the content and boundaries of the field are, and what they should be. A three-hour colloquium at the March 2014 American Association for Applied Linguistics (AAAL) meeting in Portland, Oregon addressed 'The state

1. We do not term applied linguistics a 'discipline' since it has little theory or research practice that is truly its own, independent of disciplines such as linguistics, sociology and social theory, education, etc. Later, we will argue that being a field on the cusp of different disciplines gives applied linguistics a huge opportunity for making a significant contribution to new knowledge. 
of applied linguistics: past, present and future' (Donovan, Malone, Riestenberg, McGroarty, Tarone, \& Wiley, 2014). The questions asked included: What is applied linguistics? and What do applied linguists do? These are not new concerns. Davies (2007), for example, examines the definition of applied linguistics in the introduction to his book on the topic. Some of the themes that he identifies as frequently debated are:

- What sort of linguistics, especially theory, do applied linguists actually apply?

- Are 'applied linguistics' and 'linguistics applied' the same thing?

- What is the relationship between the aspirations of applied linguistics and its scope in practice?

- How much of applied linguistics is, and should be, occupied by issues in second language teaching?

- What is the relationship between applied linguistics and second language acquisition research?

Bygate's (2005) reflections on the first 25 years of the journal Applied Linguistics include discussion related to the last two themes above. He observes that applied linguistics had, historically, a strong relationship with language teaching, which gradually extended to the study of second language acquisition, before theoretical developments in the latter created distance between them. Then, more recently, applied linguistics came to encompass many other areas, including "forensic linguistics, speech and language therapy, sign languages, the study of the language of public debates, and work with health professionals on their interactions with clients" (Bygate 2005:568). These research areas also sustain their own separate identities and communities to a greater or lesser extent, however.

Juliane House (2009, p.6) also identifies "a broad spectrum of themes in applied linguistics", which includes

first, second and foreign language learning and teaching, bilingualism and multilingualism, discourse analysis, translation and interpreting, language policy and language planning, research methodology, language testing, stylistics, literature, rhetoric, literacy and other areas in which language-related decisions need to be taken.

For her, this range is possible because "applied linguistics is not 'linguistics applied'”. In her view, applied linguistics "deals with many more issues than purely linguistic ones, and ... disciplines such as psychology, sociology, ethnography, anthropology, educational research, communication and media studies also inform applied linguistic research" (p.6).

A distinction between 'applied linguistics' (A-L) and 'linguistics applied' (L-A) is recognised by others too. Drawing on Widdowson's (2000) position, Davis \& 
Elder (2004) go as far as to allocate the chapters in their book to two parts, with these headings. While acknowledging that, in retrospect, "the L-A/A-L distinction is sustainable only at the extremes" (p. 12), they lay out the difference they sought as follows:

A-L looks outward, beyond language in an attempt to explain, perhaps even ameliorate social problems, while L-A looks inward, concerned not to solve language problems 'in the real world' but to explicate and test theories about language itself. So L-A uses language data to develop our linguistic knowledge about language, while A-L studies a language problem ... with a view to correcting it (p.11).

Figure 1, a schematic representation of Davies \& Elder's definition, places linguistic theory at the core of the applied linguist's activities. This stance reflects a longer standing position within applied linguistics. Corder (1973:7) stated, "I am enough of a purist to believe that 'applied linguistics' presupposes 'linguistics': that one cannot apply what one does not know". Yet the fact that Corder needed to make the case at all suggests that not everyone agreed. Certainly today it is not safe to assume that all applied linguists have a grounding in linguistic theory. Comparing the definitions, or absence of them, in recent handbooks dedicated to applied linguistics, Chapelle (2013) observes that there is a mismatch between the aspirations of its coverage - any domain of activity where an understanding of language might inform practice or policy — and what (most) applied linguists actually do. She suggests two reasons for this non-alignment. Firstly, the majority of those in applied linguistics are from a narrower background than can adequately offer expertise across the range of potential applications of linguistics. The other is that you don't have to be an (applied) linguist at all, to contribute expertise to the wider set of domains in which language is a variable of interest.

Chapelle's first point is potentially pertinent to the question of linguistic theory, since it reflects at least in part the fact that many applied linguists enter academia from a previous career teaching English as a foreign or second language. This trajectory has several strengths - teaching experience, good communication

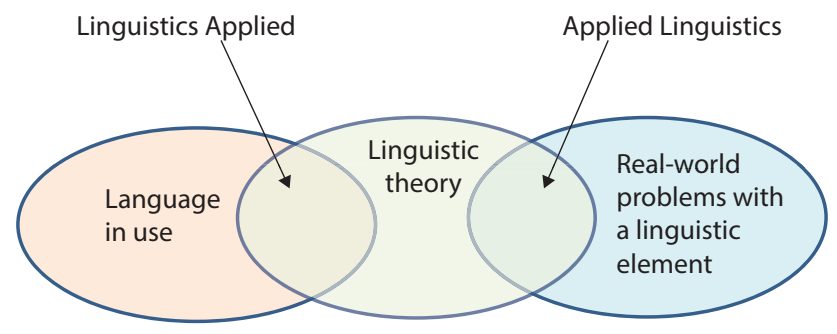

Figure 1. The domains of Linguistics Applied and Applied Linguistics, as defined by Davies \& Elder (2004) 
skills, curiosity about the practical and theoretical challenges of language teaching and learning, and the organisational skills and discipline that come from career maturity. However, it also means that many of those entering postgraduate studies and a career in applied linguistics do not have a first degree in linguistics (Hall, Smith \& Wicaksono 2011:15). As a result, they do not enter postgraduate study with the core knowledge that would assist them in taking a broad and integrated view of language form and function during that period when they are developing their researcher identity. The extent to which this lacuna can be made good depends on the content of postgraduate training provision. And here, national differences in how postgraduates are trained become significant. $\mathrm{PhD}$ programmes that have a major pre-dissertation coursework component, as in North America, have the potential to provide an extensive opportunity for breadth of learning beyond the domain of the specific dissertation topic. However, the structure of the $\mathrm{PhD}$ varies around the world, and in many countries the emphasis is on the depth of the doctoral research project, with little if any formal coursework beyond the Masters level. ${ }^{2}$

If applied linguists vary in their capacity to bring breadth of knowledge from linguistics into their research, on what basis are they sustaining it? One answer can be drawn from Chapelle's second point, that researchers from several disciplines contribute to applied linguistics research. They bring with them knowledge of educational theory, cognitive theory, philosophy, social theory, and so on, and, as a result, research that is designated 'applied linguistics' can often be anchored much more securely in these domains than in linguistics. It follows that applied linguists have a choice about which theory they engage with.

Figure 2 captures different ways in which applied linguistics research can be done. The Davies \& Elder (2004) distinction between applied linguistics and linguistics applied remains at the top. But there is now also an intersection between

\footnotetext{
2. For example, the UK PhD is three years of research, typically with no coursework. Although acceptance onto a UK PhD in applied linguistics would typically be dependent on having a good quality Masters, the pathway to $\mathrm{PhD}$ may place more emphasis on Research Methods than specialist subject content. Meanwhile, although a first degree in linguistics would be viewed as an advantage, it is unlikely to be a prerequisite in all universities. Applied linguistics is not exclusively taught and supervised in linguistics departments - Education, Social Science, English, and Modern Foreign Languages departments may also host applied linguists. The gradual introduction of more structured, 'taught' or 'professional' doctorates in the UK and elsewhere, and of a " 2 (taught) +2 (dissertation)" model rather than the currently dominant " $1+3$ ", draws the UK closer to the North American model, though not necessarily sufficiently to introduce the broader range of linguistics areas. For all postgraduate provision, there is a difficult balance to draw between the development of depth of knowledge versus breadth, particularly when there are severe constraints on how long a student can afford to study.
} 


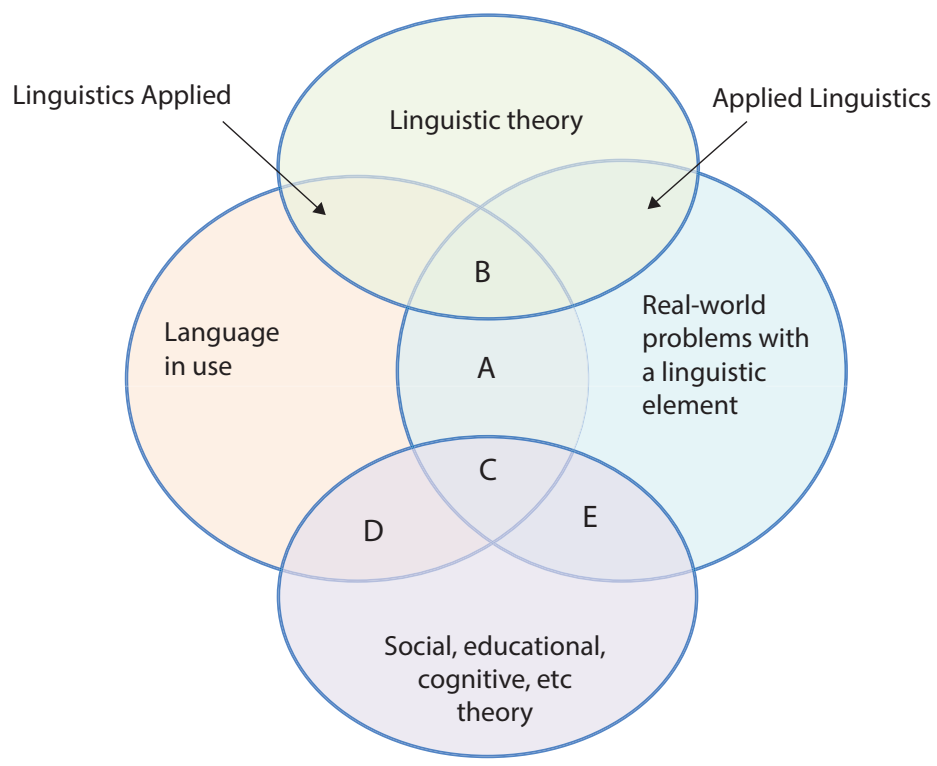

Figure 2. The broader set of domains in which applied linguists work

language in use and real-world problems (sector A). For example, research into corpus-informed language teaching does not need to engage with a model of language per se, though of course it could (sector B). Figure 2 also shows three ways $(\mathrm{C}, \mathrm{D}, \mathrm{E})$ in which linguistic theory might not feature in applied linguist research that nevertheless remains rooted in theory of one or more other kinds. In sum, if we include social, educational and cognitive theory only in its intersect zones, we have ten ways in which observations about language can be made, of which nine (that is, excluding linguistic theory outside its intersect zones) could be viewed as within the domain of applied linguistics. ${ }^{3}$

These nine domains can help explain how applied linguistics is flexible enough to draw in and develop research across such a wide range of topic areas. Indeed, the fact that applied linguistics occupies a zone of intersections may actually nurture the emergence of new specialisms. As important questions are raised about some aspect of language in the world, or as some new technology becomes available for examining the nature of language as a phenomenon and/or language in

3. Research undertaken in the zones of 'language in use' and 'real world problems', and at their intersection (A) constitutes much of the 'spade-work' that applied linguistics requires in order that theory can be developed. On its own, however, it is limited by being descriptive, and may be less attractive to funders and score less well in some quality assessments, because the absence of theory reduces the capacity to generate explanations or predictions. 
use, it is possible to reach across methods, theories, applications and evidence types to address or work with them to maximum effect.

In the final section, we will propose that this capacity to draw information and approaches from across boundaries puts applied linguistics in a particularly strong position to contribute to today's research challenges. We will further suggest that there is scope for applied linguistics to develop a new core identity that builds on its occupation of this zone of intersections.

But what does this extended zone of enquiry mean in practice for applied linguistic researchers? How does one become good at applied linguistic research? Is it sufficient to occupy one theoretical home and examine language from there? If so, then how is it possible for the findings to remain integrated? In the next section, we report the views of a selection of applied linguists who have attained international standing as researchers, regarding the nature of their enterprise and how they developed it.

\section{Exploring expertise in the context of applied linguistic research}

\section{The nature of expertise}

As the discussion below will illustrate, in some domains, an 'expert' can be fairly easily identified (e.g. by the number of trophies won). However, in the context of social science research, we shall favour the concept of 'expertise' over that of the 'expert', though our informants used both terms. Our core concern is with enhancing support for researchers' development. We find the notion of 'expertise' - something you have (to a greater or lesser extent) - helpful in drawing attention to the potential for gradually acquiring more of it. In contrast, the notion of 'expert' - something you are (or not) - risks deflecting attention from that very scope for incremental enhancement which represents the foundation for developmental intervention. As the data indicate, 'expertise' in the social science research context is perceived as multifaceted, context-bound and potentially transitory. It is also a continuum. Labelling someone an 'expert' social science researcher could tend to attribute some rather more stable set of characteristics, as if they were equally valid in all contexts. See Section 3 for further discussion.

Ericsson (2006b), writing generically about the phenomenon of expertise, defines an expert as someone who displays a consistently high level of performance within the relevant domains of activity, and who has accumulated a depth of experience. Schraw (2006) adds that an expert has a quantity of integrated knowledge, a capacity to apply sophisticated mental models to critical thinking and problem solving, procedural skills that are well-rehearsed and automated, and the ability 
to self-monitor. A further element is the authority to teach others (Chi, 2006), something that derives from recognition as an expert by others (Ericsson 2006b).

Generic considerations of expertise typically come from one of two directions. Accounts deriving from psychology define it as an personal, cognitive phenomenon. That is, individuals possess some combination of skills and knowledge that mark them out as experts. Since research into such things as the thought processes associated with expertise requires a reliable basis for identifying experts, it typically focuses on types of expertise that are extrinsic and unequivocal - those in which "by looking at how well an outcome or product is received, one can determine who is or is not an expert" (Chi, 2006, p. 21). For example, in games and sports - chess is a classic example - the most expert player is precisely that person who wins most games. This is quite different from expertise as a humanities or social science researcher, which is not necessarily epitomised in, say, how many papers someone has published, or how much research income they have won, even though both can be indirect indicators of expertise.

The other main approach examines expertise as a social phenomenon, with much more emphasis on the social construction of expertise, its ephemeral and contingent nature, and the conditions under which an individual can be recognised as 'expert', in the absence of extrinsic definitive markers such as 'games won'. Thus, for Mieg (2006:743) the primary determinant of the label 'expert' is "that you are regarded or addressed as such by someone else," (see later discussion) and this construction of expertise can match or fail fully to match some more objective measure of superior performance (ibid: 744).

Neither aspect of expertise alone captures the whole phenomenon, however, and Hoffman (1998) argues that both are necessary:

The knowledge - in a sense - must exist inside heads. Where else could it reside? As an analogy... when the expert carpenter leaves the workshop, something does leave with him. Could you or I use the tools to build, say, a china cabinet? However, knowledge - in a sense - is an attribution that resides in social groups. How else could it be developed, taught, or standardized? How could someone be regarded as an expert if her judgments are not followed in the decisions made by other people? (Hoffman 1998: 94)

In domains where expertise is, at least to a significant degree, in the eye of the beholder, it is typically peers, formed up as some sort of professional institution, who determine who has expertise and what the qualifying criteria are. Thus, applied linguists, as a community, act as gatekeepers in a variety of ways, applying standards of research quality that are largely emergent - they sit on the committees of $\mathrm{PhD}$ candidates and/or examine their dissertations; shortlist candidates for academic posts; preside over tenure and promotion applications; review abstracts 
for conferences, papers for journals, and applications for funding; elect leaders to their associations; and invite plenary speakers to their conferences.

What is it that the community sees in those given the accolade of possessing expertise, and how do those with expertise see themselves? What knowledge and skills do they have, and how did they acquire them? What aspects of their own development do they prioritise now that they have responsibility for developing others? Our own small-scale perception study, to which we now turn, sought some preliminary answers to these questions.

\section{Study design}

\section{Rationale}

Between 2010 and 2014 we conducted a project under the auspices of the Researcher Development Initiative of the UK's Economic and Social Research Council (ESRC). Its aim was to develop research-informed and trialled training tools for mid-career researchers in the social sciences. It was inspired by the recognition that although there are many types of support for $\mathrm{PhD}$ students and early career researchers, there is little to help mid-career academics develop their expertise further. Indeed, mid-career academics tend to be expected to behave as if they already have attained substantial expertise: to win research funding and publish high quality research outputs, for example, and to advise and support students and more junior colleagues in developing their own potential.

As a starting point, we drew on our experience as trainers and mentors plus, in the case of one of us (MW) as the ESRC's Strategic Adviser for Researcher Development (2009-2012), and in the case of the other (AW) ten years as the director of research for an academic community composed of three disciplines spanning the social sciences and humanities. These experiences suggested that mid-career colleagues often struggle with their sense of credibility as supporters of others, and do not necessarily find it at all easy to develop and sustain high quality research activity in the context of the other demands of their job, particularly teaching and administration. ${ }^{4}$ Many find it hard to undertake much research at all without working long hours and sacrificing family and holiday time, and there is a risk that short cuts have to be taken that, even if not too evident on the surface, can progressively eat away at the individual's sense of professionalism and academic worth.

4. Both inter- and intra-national differences apply in the typical experience of academics, of course. Our personal experience is in the UK context, where it is universally acknowledged that research and scholarship time are heavily compromised by increased teaching loads and how administrative functions are balanced between academic and support staff. 
Against this backdrop, we conceptualised the project to develop training materials that could assist mid-career researchers ${ }^{5}$ gain confidence, reconnect with the creativity they had as postgraduates (often lost in the context of heavy teaching and administrative commitments), and accelerate their development towards greater research expertise.

\section{Design}

There were three main components. Firstly a literature review was conducted, to locate social science research expertise within a broader frame of 'expertise' more generally. Secondly, in-depth semi-structured face-to-face interviews of up to 90 minutes each, or equivalent electronic written interviews, were conducted with 31 researchers identified as possessing high level expertise in a social science discipline, primarily in applied linguistics and business and management (see below). The purpose was to establish what it was that they saw in themselves and others, how they had developed their skills and knowledge, and what support they offered to their students and junior colleagues. Thirdly, drawing on the first two components, training materials were designed and trialled in different workshop settings. A training manual was developed and, after peer review, published on the internet for free use by senior academics with responsibility for staff research development (Wray \& Wallace 2014).

\section{Participants}

Given the breadth of the social sciences - the ESRC lists 19 constituent 'disciplines' on its website ${ }^{6}$ - this study could not feasibly examine researchers from every relevant domain. Instead, the two ESRC 'disciplines' or research domains in which we ourselves work were made the primary focus: applied linguistics $(n=17)$ and business and management $(\mathrm{n}=11)$. This approach meant we had a clear sense of where the researchers with most expertise were likely to be found, and we had a credible basis on which to approach them. In addition, three informants from other social science disciplines were included, because they had particular knowledge or experience relevant to the project.

Participants were selected as those likely to be recognised by the community as having expertise. To meet this criterion, the person had usually carried a prestigious role, such as the president or chair of a national disciplinary association (such as AAAL, BAAL or the American Academy of Management, AoM), editor

5. As the work was funded by a UK research council, our primary target was UK researchers. However, the responses during the project, and the reception of the training manual subsequently, strongly suggest that the findings and ideas are relevant beyond the UK.

6. http://www.esrc.ac.uk/about-esrc/what-is-social-science/index.aspx 
of one of the international journals for the discipline, or plenary speaker at one of the annual international disciplinary conferences. In addition, we consulted some of the individuals so-identified, for suggestions of other people who in their opinion exemplified research expertise in their discipline.

\section{Method}

Face-to-face interviews were conducted during international academic conferences or during academic visits by informants to our location or us to theirs. Other interviews were conducted by email. In all cases, participants were first approached with a request for the interview, at which point the purpose and nature of the study was explained. Face-to-face interviews were audio-recorded in a quiet and private location where feasible. For email interviews, a list of questions was sent to the participant, and written answers were sent back. In most cases, the answers were sufficiently self-explanatory for no further questions to be required. But in cases where it would be useful to follow up on issues raised, we instigated an email exchange to augment the information.

All participants were guaranteed anonymity, and consequently their quoted observations below are not attributed. The audio-recorded interviews were transcribed, and analysed using a detailed grid of parameters relevant to the research questions. A quote bank was constructed for inclusion in the training materials. The questions asked in the interview are provided in Appendix 1, and the main questions for the literature review are given in Appendix 2.

\section{Conceptualising 'expertise' in the context of applied linguistic research}

The discussion will be framed around the four questions listed in Section 1:

- Who decides who are the leading researchers, and on what basis?

- What are the characteristics of current leading researchers, and of the work they do?

- How are the knowledge and skills in field-leading applied linguistic work developed?

- How were those who have acquired research expertise supported in developing it, and how do they now support the up-coming generation of less-experienced researchers?

Selected observations from the literature review will be used as a stimulus for exploring the key findings from the applied linguists who participated in the study. The quotes are coded to indicate gender (F, M) and the informant's location: 
NA (North America), UK (United Kingdom), EU (Europe), ${ }^{7}$ AS (Asia), ANZ (Australia and New Zealand). A much larger set of quotes, covering the entire participant group, is available as a resource bank from the project site. ${ }^{8}$

\section{Who decides who are the leading researchers, and on what basis?}

There was clear acknowledgement that expertise is not primarily about what you think of yourself - whether good or bad - but what others think of you. As one applied linguist observed,

[expertise in applied linguistics research] is not an objective quality. It requires a certain amount of recognition from the community for you to be defined as an expert, and that recognition may be slower or quicker in coming ... expertise is a two-place predicate ${ }^{9}[\mathrm{UK}, \mathrm{m}]$.

His view is in keeping with that of Agnew et al (1997:220), that socially-conferred expertise "does not reside in the individual, but rather emerges from a dynamic interaction between the individual and his physical/cultural domain." There are several consequences. One is that there is no guarantee that those with the most expertise in any more objective sense will necessarily be the ones to gain the accolades of 'expert'.

Whether or not an individual is selected to serve in an expert role for a constituency is often independent of the absolute accuracy of their knowledge. Experts are not necessarily the most knowledgeable among us (Agnew et al 1997:220).

More cynically put, "an expert is anyone who can persuade someone else that he (she) is an expert" (Shanteau 1988:209). Agnew et al further propose that

cultural and disciplinary constraints select the fittingest. We say 'the fittingest' not the 'fittest', thus indicating that in studying expertise we must focus as much upon the selectors (the context) as upon the selected (the experts) (p.221).

Collectively, these views suggest that we might find accounts of expertise within applied linguistics to be tied into currently relevant needs and interests within the

7. As a UK-based and funded study it was appropriate to separate UK responses from those given by informants from other European countries. Additionally there are substantial differences between the postgraduate training and employment contexts in the UK and most of the rest of Europe.

8. www.restore.ac.uk/researchexpertise

9. A two-place predicate requires, to complete its meaning, two other elements, not one. You can't just have expertise - someone else has to be involved, to perceive you as possessing it. 
field, and this is, indeed, what the following sections demonstrate. Importantly, notwithstanding Agnew et al's suggestion, there was no evidence that our informants had specific awareness of their individual or collective power to define who had expertise. In the absence of such evidence, the default assumption would be that they expected others' expertise to be recognised as a natural and reliable consequence of their meeting the criteria associated with excellence.

On the other hand, it was striking how many of them felt uncomfortable about being seen as an 'expert' themselves - a pattern observed across all national groups. Although they readily acknowledged that they were viewed by others as having high level expertise, there was a strong tendency for them to doubt that they fully deserved that status. There were two different reasons. Informants were insecure about their knowledge, and dubious about the value of being trusted to know best. This feeling was not exclusive to the applied linguists in the study, but was more pronounced than it was in the business and management community. This may be related to the observations made earlier about the breadth of knowledge that applied linguistics potentially covers. On the other hand, as we shall see, for many, expertise came into its own precisely at the point when their knowledge ran out.

The other reason for concern about being labelled 'expert' related to expectations:

I think there is a danger in regarding people as experts. Anyone who eventually gets that title usually realizes that they have enormous gaps in their knowledge. One of the problems is that that unofficial title blinds people to the weaknesses in the research of 'experts'. Just because an expert says or does it, does not mean that it is correct. Once experts start believing in their own expertness, we are in deep trouble. [ANZ,m].

This comment resonates with Mieg's (2006: 748) suggestion that expertise is recognised as "an extension or generalization of one's own experience," (original emphasis) and that it is assigned to others as a means of reducing a sense of uncertainty about the world. By granting a stable authority to someone, it becomes possible to trust them to know as much as needs to be known. Inevitably, this dynamic renders expertise vulnerable both to the insecurities of the 'expert' and to changes in the focus of attention within the host community.

What are the characteristics of current leading researchers, and of the work they do?

The main characteristics identified related to:

- knowledge and skills 
- boundary-pushing

- communication

- personality traits

- collaboration

\section{Expertise as an accumulation of knowledge and skills}

The applied linguists acknowledged that expertise entails the command of a broad and integrated body of knowledge:

An expert is 'up' on the topic at hand, familiar with the range and breadth of the field, knowledgeable about ancillary fields, follows particular writers, researchers, journals and topics [NA,f].

However, as noted above, our applied linguist respondents - with rather more regularity than those from business and management - commented on the evident limits to expertise in terms of knowledge. One commented, "I know I'm operating most of the time very much at the edge of my capabilities" [UK,m].

Schraw (2006) suggests, in relation to expertise more generally, that it entails the capacity to extrapolate to new contexts by applying mental models of existing knowledge, and the ability to deploy critical thinking to self-monitor and solve problems. Thus, someone with expertise in applied linguistics "should...have lots of experience in doing research so that they can appreciate the difficulties of operationalizing research" [ANZ,m]. In a complex domain of enquiry, one cannot know everything, of course, so it is likely that "some experts may be stronger in theory and others in methodology" [NA,f]. Nevertheless, "an ideal expert should blend the knowledge and understanding of both aspects" [ibid.].

Knowledge and skills are the result of experience that is characterised by increasing incidences of high level performance (Ericsson 2006b).

I learned by experience. I progressed from smaller projects to larger ones and periods of reflection on what we had learned were helpful. I imagine this is pretty typical of the experience of most applied...linguists involved in research projects $[\mathrm{ANZ}, \mathrm{f}]$.

It is experience that furnishes the 'expert' with the authority to set standards for others (Shanteau 1988:205-206). It renders depth of perception - "an ability to take a step back and see the forest beyond the trees" [NA,f], and the capacity to make appropriate judgments about what is possible and useful, and to ask good questions: that is,

[questions] that others in the field would...immediately recognize as important to be answered...'Good' means ... answerable in principle or even in practice with what we know today... [NA,m]. 


\section{Expertise as boundary-pushing}

Feltovich, Spiro \& Coulson (1997) consider the accumulation of experience to have two contradictory effects. On the one hand, it enables the routinization and schematization of actions, shortcuts in reaching judgments and, hence, an increasingly circumscribed route through thinking. As Wright (2013), examining the expertise of police detectives, puts it,

The psychology of human inference demonstrates that keeping an open mind is simply not possible; in the absence of information, individuals extrapolate and frame problems on the basis of their prior knowledge and beliefs (p. 193).

On the other hand, experience entails exposure to more variables, enabling flexibility of response (Feltovich et al 1997). The balance between these two, including the capacity to optimize responses to novel situations by fast-tracking the nonnovel components, is sustained by the capacity to detect what is unusual in the situation.

The applied linguists did not explicitly acknowledge the routinized element. They characterized expertise as the transcendence of the normal procedures, pushing at the boundaries of existing knowledge and developing ideas in new directions. Thus, an applied linguist with expertise was

Somebody who can change the way I think about something by asking me questions that force me to put knowledge into different relationships from what I had before, and give me tools for thinking about it differently. What's exciting about talking to an expert I think is when that person is able to make you see new horizons for the boundaries of their knowledge [NA,m].

Expertise entailed being "able to ... sniff out something that [is] absolutely critical... that has social currency, not just academically, but financially, organizationally, socially, culturally, artistically" [ANZ,m]. One informant noted the importance for his own thinking of engaging with others:

What I like to think I'm good at is crossing boundaries...I like to hear what people of a different perspective on a general topic area have got to say. I find myself immediately thinking, how can I turn what they've said into something that I could capitalize on in my own work? [NA,m].

Applied linguists were quick to recognise the importance of interdisciplinary engagement, and of the opportunities it brought for understanding a phenomenon better:

The first quality is to try to be open to understanding another point of view. But, this is not something that can be done superficially or selectively. One has to truly learn to think differently. One of the challenges of interdisciplinary collaboration 
is the need to remain as true as possible to how ideas are portrayed in the allied discipline $[\mathrm{NA}, \mathrm{f}]$.

The same informant commented on the importance of reading in other fields and disciplines, "to understand the limitations of one's own professional upbringing." Different disciplinary traditions have different perspectives on the same phenomenon:

psychologists and linguists often articulate very different research questions, make different assumptions, and apply different methods, as a result speaking past each other. Interdisciplinary collaborations help us evaluate each other's assumptions, reassess our own, combine methodologies in order to satisfy requirements in each field, and find ways to speak to each other [NA,f].

However, there was also recognition that expertise in applied linguistics entails navigating approaches within its own domain, particularly across the divide between qualitative and quantitative methods:

to me it's a completely false divide. It shouldn't be there...I see far too much still where people are entrenched in one or the other, and they think somehow there is a hierarchy $[\mathrm{NA}, \mathrm{m}]$.

it seems to me magical that, for example, statistics experts be involved in work with colleagues doing qualitative research $[\mathrm{EU}, \mathrm{m}]$.

According to Collins (e.g. 2007), the capacity to engage effectively across boundaries requires a particular kind of expertise, which he terms 'interactional expertise'. It

turns on fluency in the language of the domain rather than hands-on experience; it is acquired more through immersion in the discourse of the hands-on experts than through participation in their characteristic practices (p. 615).

What Collins recognises here is that there is a knack to managing the challenges of venturing beyond one's knowledge comfort zone. There is a major risk in interdisciplinary or inter-method engagement that one develops shallow knowledge, which is disguised by the apparently appropriate use of terminology. His research examines the relationship between 'talking the talk' and, in the absence of the time or opportunity to develop full expertise in another domain and thus 'walk the walk', successfully interacting with others by knowing how to 'walk the talk' (Ross, 2008).

Engagement with others has the effect of challenging the researcher to remain circumspect about his or her own knowledge, and be willing to adapt in the light of new evidence: 
I have...somewhat revised my definition of good scholarship. I now think that an expert is someone who remains open, questing - prepared to shift perspectives, even whole theoretical commitments - when the evidence suggests that they are no longer worthy $[\mathrm{NA}, \mathrm{f}]$.

\section{Expertise and communication}

It should probably not surprise us that applied linguists spoke about the importance of being able to communicate one's knowledge to others. Although other social science informants implicitly valued this skill, it tended to be in the more utilitarian context of writing appropriately for publication. For the applied linguists, though, it was a matter of connecting:

[An expert is] somebody who can write about [their research] really well and somebody who can stand up and talk about this in a very persuasive and clear way $[\mathrm{ANZ}, \mathrm{m}]$.

The applied linguistics experts I know have a remarkable ability to communicate very clearly the important insights they have gained from their research. They are good researchers and good communicators [ANZ,f].

\section{Personal characteristics associated with expertise}

Across the entire study cohort a range of personal characteristics were identified. The applied linguists had considerably less to say than the business and management researchers about toughness, ruthlessness, ambition and focus. They did, however recognise the importance of persistence and emotional maturity:

[An expert] keeps working until a problem is solved" [NA,f].

In my view a successful researcher needs the skills of effective management, that is, a great ability to manage one's own emotions, to reduce anxiety common among those engaged in intellectual pursuits, and to dominate negative emotions common in responses to criticisms of one's own work [NA,f].

The issue of ego in research and willingness to admit...that they changed their minds or they found something wrong that they did before...in my mind that makes them more expert [UK,f].

Another important trait identified by the applied linguists - it was also often mentioned by the other social scientists - was generosity:

Someone once said, you can accomplish anything if you don't care who gets the credit for it. I think that's a tremendously wise thing, and it works' [NA,m]. 
Someone who cares about junior people will give them opportunities, will introduce them to people, will author papers with them...you're hands on with these people until they can pretty well do it themselves' [ANZ,m].

\section{Expertise and collaboration}

In the light of current trends towards addressing major social questions through interdisciplinary teams, the study participants were asked to comment on the relationship between expertise and collaboration. There was consensus of its importance, with comments that resonate with and extend the accounts, earlier, of the role of effective communication and boundary-pushing.

One theme emerging was the opportunity for collaborations to amount to more than the sum of the parts:

One of the things I have learned is that if you just put half a dozen smart people in a room together you don't have to have too much of an agenda for something good to come out of it, as long as people obey certain social rules such as respecting each other, being flexible and letting ideas flow together [NA,m].

However, not all approaches to collaboration are equally effective:

I've seen two ways of collaborating. One is less likely to be successful...you have a perspective on a topic which is different from my perspective on a topic, and it's kind of interesting to hear what we each have to say. But neither of these perspectives has a real impact on the other. [The other approach] is to develop this larger picture of the problem which makes both perspectives absolutely indispensable and inherent in that larger picture...So it's not just interesting add-on to their work, it's a necessary component and they have to feel the same about yours $[\mathrm{NA}, \mathrm{m}]$.

An important element in how collaborative discussions work is "Seeing the world through someone else's eyes" [UK,f], for "You have to move out of your comfort zone ... and ... not worry about the fact that you don't know the answers" [UK, $\mathrm{m}]$. "You have to be willing to accept ideas of other persons, back up and let others take the lead as well as you" [NA,f].

The recognition that not all knowledge is shared is an important catalyst, enabling one to ask 'stupid' questions, and requiring one to explain to others things that one might otherwise not adequately articulate for oneself:

When you feel there's a clash, that something's not quite being mutually understood and then pushing through and saying 'well, what actually do you mean by that?' [UK,f].

[the collaborator] doesn't really know the things I'm talking about. 'What do you mean, the type-token ratio? What do you mean, the sentence length?... What are 
the constructs you're using? Are they meaningful?' But actually by having to explain it, it becomes clearer to you yourself, what it is that you're doing [EU,f].

Effective collaboration is only possible if the process is enjoyable, and the context is appropriate:

People enjoy it as they feel they're getting involved, they're contributing something and they're learning something...but if it isn't fun and people feel they're being socially pressured to do things that they wouldn't otherwise want to do, because they don't have time for it, it's going to fail [NA,m].

[In the past] I realized I really enjoyed working in a team and I have done so ever since. I am good at working with others and coping with many different workstyles, and this has been a real asset $[\mathrm{ANZ}, \mathrm{f}]$.

Collaboration is not easy to create and sustain, however:

I think special skills are required in collaborating and they are personal skills as much as research skills [ANZ,m].

I do know that some experts are difficult to work with, but there are also some who are easy to work with and are open to new ideas. I consider myself easy to work with, but I know not everyone around me thinks so. Collaboration does not always happen $[\mathrm{AS}, \mathrm{m}]$.

As a result, "withdrawing from collaborations is another thing you have to be expert at" [UK,f].

How are the knowledge and skills in field-leading applied linguistic work developed?

individuals who eventually reach very high levels do not simply accumulate more routine experience of domain-related activities, but extend their active skillbuilding period for years or even decades (Ericsson 2006a: 691).

Although the essential elements of expertise are often considered to be tacit (e.g. Dreyfus and Dreyfus 2005), our informants had little difficulty in talking about what they felt they had learned in the course of their journey towards expertise. However, they did not always focus on the same aspects as arise in the literature. This may be a reflection of different types of expertise, of the levels of expertise under discussion, or of the relative invisibility of some elements. For example, a strong theme in the research on the emergence of expertise over time is the restructuring of knowledge. As Feltovich et al (2006) put it, 
Experts restructure, reorganize, and refine their representation of knowledge and procedures for efficient application to their work-a-day environments...experts certainly know more, but they also know differently (p.57).

Chi et al (1982) compared how undergraduate and postgraduate students solved problems in physics. The postgraduates referred more to underlying principles, whereas the undergraduates attended mostly to surface details.

The limitation of the novices derives from their inability to infer further knowledge from the literal cues in the problem statement. In contrast, these inferences necessarily are generated in the context of the relevant knowledge structures that experts possess. (p.71).

This capacity to create more abstract representations of knowledge is also relevant to the social sciences in general and applied linguistics in particular:

When I was a PhD student, I tried to think about questions in...the more conventional way, which is to be more linear. And to say, 'Well, this research... produced these findings, and if we extrapolate that, then we should find this...' [But now] I won't be excited unless I can see how it fits into a bigger picture of some sort $[\mathrm{NA}, \mathrm{m}]$.

Generally, the applied linguists pointed out certain key skills that they felt they had not had earlier in their career. One was critical reading [NA,f]. Another was having a clear sense of how the existing research fitted together:

I remember the feeling of frustration I had after writing my first book...At that point I was aware that I had read most of what was written about [the topic], but I did not see clear avenues of research arising out of that. It was not until several years later that $\mathrm{I}$ began to get a clearer picture of what research needed to be done [ANZ,m].

A third element was becoming streetwise about how to work effectively, e.g. "I have learned to plan ahead, to set objectives and review them regularly..." [ANZ,f].

The key change in my own thinking is that I no longer think of my professional activities in terms of 'publishing' but in terms of social relevance, scholarly importance, and impact...Given the limited time-frame we all have for any kind of meaningful activity, this approach leads me to prioritize activities I design myself (i.e. my own studies, books, and articles) and turn down most of the invitations I get, because they advance other people's agendas rather than my own [NA,f].

Although developing one's own new ideas imaginatively was key to performing at a high level, nevertheless it was important, in one informant's view, to keep one's feet on the ground: "Perhaps I show more respect for facts than years ago, when I would stick to certain facts while ignoring others" [AS,m]. 
Experience also teaches one to recognise and value one's own strengths, and have confidence in working with them:

I think I've learned that I'm better at conceptual theorizing than at empirical research. In the beginning I was doing lots of empirical work... but I wasn't creative at it, and it appeared, at least to me, that I enjoyed and was better at trying to speculate about the big picture [NA,m].

Notwithstanding the character traits mentioned above, all these views are consistent with the idea that expertise can, and indeed must, be learned. To put it another way, none of the informants expressed a belief that their own status had been inevitable or guaranteed on account of ability or personality. Rather, they implicitly concurred with Sosniak (2006:300) that

Expertise is not an endpoint, it is a continuum...studies will allow us to frame and text meaningful opportunities for advancing the development of talent, however far, for ever-expanding numbers of individuals.

This being so, it is important to understand how the development of expertise is best nurtured in junior and mid-career researchers.

How were those who have acquired research expertise supported in developing it, and how do they now support the up-coming generation of less-experienced researchers?

Two broad parameters can be identified in how the informants spoke about supporting researchers towards developing their own expertise. One is direct input. The other is the creation and sustaining of a conducive environment for learning. The latter entails both interaction between those with greater and lesser expertise - for example in a research project or mentoring arrangement - and the wider responsibility that many senior academics have for shaping the research environment of their colleagues through leadership and management roles. These parameters are not entirely independent, because the capacity of one person to support another is contingent on the local conditions. For example, it will constrain a senior researcher's ability to take more junior staff to conferences as co-presenters, if there is no financial support for the travel. It will be difficult for effective collaborative writing to take place if one or both parties are too busy with teaching and/or administrative duties to turn drafts around promptly.

In the workshop element of the project, such constraints were often mentioned, and it is important that a pragmatic and constructive approach is taken towards addressing them. Wray \& Wallace (2014) offer an extensive list of recom- 
mendations to senior academics with responsibility for researcher development, that aim to maximise the effectiveness of whatever resources are available.

One of the most resource-heavy, but potentially effective, ways of supporting researchers towards greater expertise is through coaching. We conceptualise coaching, in the research context, as a means of facilitating self-determination while benefiting from the best features of effective mentoring (Wray \& Wallace 2011). Coaching is a short term, targeted intervention that might too easily be construed in the academic context as remedial. However, in the private sector, coaching is a reward offered to the most talented, as a means of helping them to the next level, and with this kind of focus, it could be used selectively to support academics at a key moment in their career, such as attaining tenure or promotion. In addition, there is scope for self-coaching, peer-coaching and coachinginformed mentoring, all of which could be deployed more broadly.

The study informants as a whole, not just in applied linguistics, reported mixed experiences about the mentoring, and indeed $\mathrm{PhD}$ supervision, that they had themselves received. For some, inadequate support had been a hindrance, while for others it had galvanised them into becoming self-sufficient. There was a general sense that almost no training is available for the sorts of skills typically needed beyond doctoral level, e.g. "There are not many opportunities to do courses on research, and such courses often lack immediate relevance" [ANZ,m]. However, most informants considered that they had largely learned by doing - both incidentally and through deliberate practice. Practice in some contexts is strongly guided:

expert performers and their teachers identify specific goals for improving particular aspects of performance and design training activities that allow the performer to gradually refine performance with feedback and opportunities for repetition (deliberate practice). The performers will gradually acquire mechanisms that increase their ability to control, self-monitor, and evaluate their performance in representative situations from the domain and thus gain independence from the feedback of their teachers (Ericsson 2006a: 694).

Some elements of this collaborative approach to learning apply in academic work, such as in mentoring and constructive peer review. In other words, learning expertise as a researcher is strongly dependent on trying things out and getting feedback:

I see anonymous peer-review as central in the expertise-building enterprise' [NA,f].

One or two colleagues were very useful in developing my research skills largely through discussion and through co-operative critiquing of research designs. Their 
main help to me came through their pointing out the weaknesses of my designs and suggesting other possibilities. I have also learned a lot through listening to others describe and justify their research designs [ANZ,m].

An environment conducive to developing high level skills and knowledge was the single most often-cited catalyst to expertise in the study sample (Wray \& Wallace 2014):

I did doctoral work in a prestigious, Ivy League US university, where I participated in conferences, workshops, and summer schools and met many prominent scholars while still a doctoral student [NA,f].

I remember being struck by this atmosphere of high-powered research that seemed to be in the air there. In the seminars it was perfectly relaxed, they didn't feel very competitive and they didn't feel stressful... a couple of profs were essential in providing that spark [EU,f].

Others referred to the value of just being around active researchers: "We can learn by osmosis, just being around people, and for me this means not being too much of a hermit, not working in a little cubbyhole somewhere" [NA,m]. "I suppose I learned by watching and reading others, listening to and engaging with them" $[\mathrm{NA}, \mathrm{f}]$. One informant noted,

I was strongly influenced in the choice of [my specialist] areas by senior colleagues I worked with early in my career. They did not direct me towards these areas but, through talking to them and observing their own research, I developed a strong interest in what they were doing [ANZ,m].

As senior colleagues themselves now, the informants often mentioned that the benefits of working with junior staff are two way: "I have ... had a succession of coauthors; sometimes I have been the senior author, other times the junior author. I am sure that I learned from both roles" [NA,f]. This capacity to learn from below should not be taken for granted. It requires a personal confidence and a generosity of spirit (see earlier). Agnew et al (1997) point out that there are natural tensions between the role of the expert in initiating new members into the community of practice and the need not to stifle the new ideas that will build the next generation of experts. These tensions need to be managed.

Importantly, teaching and co-authoring, along with writing, are examples of learning by doing. All of them require one to think through and repackage one's knowledge to make it comprehensible to others:

[One] thing that really helped was teaching research methods, 'cos it just forces you to be very clear and present [information] to others...You're selecting work to illustrate the methods and you're evaluating it with your students, so that means 
you need to work towards that deeper understanding where you can evaluate something $[\mathrm{UK}, \mathrm{f}]$.

When I look back over my career I realize that a lot of my learning came through having to write about what I was reading... Whenever I teach a new course my immediate goal is to write a book that covers the ideas in that course...I find that through having to write I need to clarify my ideas, and that sends me back to critical reading and thinking about what I have read $[\mathrm{ANZ}, \mathrm{m}]$.

Agency and the responsibility to make the environment work for others were a recurrent theme:

See yourself as a citizen in your context where you do your work. You cannot do your work in isolation, so you're dependent on the environment that surrounds you. So the first thing is, you're not entitled to anything...you have to make the environment work for you $[\mathrm{NA}, \mathrm{m}]$.

I think the role of the head of department is to set up a situation where it's okay for people to do research and talk about it. If you can get that atmosphere going, most other things will follow from it [UK,m].

It's to do with me hanging out in my office and being able to chat to people when needed, but they chat to each other and we have meetings where we talk about shared issues...it's that kind of community which is absolutely paramount...for making any kind of apprenticeship work in academia...There are lots of conversations going on and I think that gets picked up by people and we're proud of that environment...So this is not just about mentoring other people, this is about me feeling part of a bigger thing which has such enormous potential [ANZ,m].

We have a very active speaker series, which gives my students opportunities to organize visits, meet and talk to well-known researchers (and get feedback on their own projects), and to see firsthand a variety of experts in the field. After the visits, I engage the students in critical discussions about what they saw and learned, and give them extra credit for papers that articulate such critical reflections [NA,f].

One informant with considerable experience as a head of department had quite specific advice:

I see this activity of changing one's environment as a Go! game, as opposed to a chess game, which most people think of it as.... With Go!, you try to build up a stable structure so you can change the environment in such a way that it becomes self-sustaining. And for me that means bringing in new ways of doing things and getting as many people invested in that new way of doing things - in such a way that it can never be undone without tremendous effort on some bad person's part...If good decisions are made, write them down and put them where 
they're accessible, so people don't forget them, and they don't just get thrown away $[\mathrm{NA}, \mathrm{m}]$.

\section{Summary observations}

In this study, we sought to find out what the characteristics of research expertise in applied linguistics are, and how researchers can best be supported in developing it. Like the other social scientists in the study, the applied linguist informants recognised the importance of imagination and creativity, and of having a depth and breadth of knowledge. However, for the applied linguists an equally important theme was what one does about the knowledge one does not have. They spoke about how one successfully collaborates with others to extend the reach of one's research, and the importance of good communication skills in ensuring that one can engage effectively in dialogue with others, without falling foul of jargon, assumptions and differences in the meaning of common vocabulary. With regard to the development of expertise, the applied linguists rarely mentioned the tacit know how that is often claimed to be core to 'true' expertise. They were able to discuss what they had learned and how, and they identified - as did our other informants - the quality of the research environment as particularly important. That is, one learns by observing others, working with them, and taking the role not only of mentee but also mentor, not only second author but also first author. Indeed, our informants were clear that they continued to develop as researchers by means of the support they gave to their students and colleagues.

So, this is how already successful applied linguistic researchers characterised the learning journey. But what of those who have the potential for high level expertise but have yet to develop it fully? We cannot ignore diachronic changes in the world of academic research. What worked for applied linguists who are now in their 50s, 60s and 70s may not work in the same way for those now in their 20s, 30s and 40s. The demands on today's academic are different, with work intensification, particularly, a potential body blow to research productivity and creativity. On the other hand, the availability of training opportunities has increased, and aspects of the research environment that were formerly on the campus are now in our own homes, from where we can consult a world class library of publications, and engage in electronic conversations with international collaborators.

Another thing that has changed is a greater expectation that research will be useful (impactful) and joined up across discipline boundaries. Research imperatives based on internationally-recognised problems are increasingly pursued by drawing on expertise from across whichever disciplines have potential to contribute to integrated solutions. How, in the present day context, might applied linguists 
best develop the appropriate skills and knowledge to maximise their capacity to contribute fully to the research agendas of our time?

\section{Developing our future applied linguists}

In this final section we draw together the themes of the paper, to consider what expertise in applied linguistics we should be supporting today's researchers to develop, and how.

\section{Maximising opportunities for growth}

The modern academic world is highly competitive. The applied linguistics community needs to protect itself against the risk of under-investment relative to other fields and disciplines that have a clearer core identity, greater consensus on canons for judging quality, and perhaps a stronger self-confidence. As research becomes more interdisciplinary, there are fewer opportunities for applied linguists to compete for resources only amongst themselves. Research funding applications are likely to be evaluated by non-specialists, against the benchmarks of the domains that are most successful in terms of self-promotion. Even funding earmarked for applied linguistics may be awarded to researchers from 'outside': a sophisticated knowledge of, say, psychology, neurology or education may obscure a lack of in depth knowledge of language itself.

In this context it is important that applied linguists know how to articulate their expertise, so as to demonstrate clearly how they will add value to an investigation, relative to those with other knowledge and skills. To achieve this, applied linguists need to know two things: what their core knowledge-base is, and how to integrate knowledge from different domains. The informants in our study were strikingly able to talk about the boundaries of their knowledge, and how working at those boundaries opened up new opportunities for learning.

Across our study, the single most important catalyst for the development of expertise was the research environment. Many applied linguists work in small units, where it is difficult to create a strong sense of identity or to exercise much power: they are variously attached to modern languages, literature, linguistics and education departments, inter alia. These differences in local environment may impact on the sense of similarity that applied linguists feel with each other, so that national and international gatherings of applied linguists become as sensitive to differences of experience and context as to similarities.

Due to the thin presence of applied linguists in most universities, arguably the single best opportunity for improving the research environment of applied 
linguists is through their learned societies. Doing so requires a considerable increase in proactivity. Given the inherent ambiguity about the definition of applied linguistics, it is understandable that the learned societies have tended to reflect rather than to shape their collective identity. Much could be done to strengthen applied linguistics if the learned societies were more active both in promoting debate to articulate desirable directions for the field, and in supporting the development of their members. ${ }^{10}$

Opportunities include:

- A clear and determined assertion of the purposes of applied linguistics and a strong definition of what constitutes good quality applied linguistic research.

- Inputs at workshops from those recognised within the community to have particular forms of expertise in applied linguistics research - setting challenges and agendas, identifying areas for development, etc.

- Workshops focussed on helping applied linguistics researchers identify and address their own strengths and weaknesses, giving them more confidence in understanding where to focus their activities and energy, and in navigating the inevitable boundaries of their knowledge.

- Clear and public articulations of what applied linguistics can offer of benefit to society, including the ways in which it could have impact on current social challenges.

- Agenda-setting events for invited partners from the public, private and charity sectors who either already believe applied linguistics expertise could assist them in achieving some desired outcome, or who might be open to persuasion if the case were made.

- Collaborative meetings with expert researchers from other disciplines, to mark out the common ground and the points at which apparently similar interests and knowledge are in fact not the same, and to develop skills for working effectively within those overlap domains.

- Debate within the applied linguistics community about ways of promoting applied linguistics as a fundable research area and as a marketable area for undergraduate and postgraduate teaching.

- Workshops to share good practice in research-led teaching, with special reference to inducting students into problem-driven enquiry that crosses traditional boundaries.

10. At the time of writing, AAAL has issued a consultation survey about the foundation of a Summer Institute. This is one welcome example of the kind of proaction that could positively influence the development trajectory of applied linguists. 
Some of these objectives could be achieved within the existing activities of applied linguistics learned societies, such as annual conferences, but more could be done. Possibilities span:

- The promotion of national and international priority research agendas within which applied linguistics has a clear contribution to make.

- Collaborations between the universities and the applied linguistics learned societies, to share expertise-development through targeted inputs or funded practical projects. This could also be a mechanism for taking the skills of applied linguists to researchers in other disciplines.

- A researcher mentoring scheme coordinated by the applied linguistics organisations, to provide access to expertise for those who do not have senior colleagues or a strong research environment locally.

\section{Maximising the opportunities within the zone of intersections}

To complement the practical activities proposed above, the applied linguistics community needs to review the range of its theoretical perspectives and approaches, and consider how research within applied linguistics might challenge and inform existing theories, and spawn new ones.

The first section of this paper demonstrated how applied linguistics occupies a zone of intersections - between patterns of language in use, language problems in the world, linguistic theory and a range of other theories, including social, educational and cognitive (Figure 2). Although there are huge opportunities arising from such overlaps, there are also risks, particularly those around falling into a superficial understanding of theory and practice that lies within the expertise of others. In the accounts of expertise in the study, collaboration was strongly favoured as a way of reaching beyond one's own boundaries of knowledge. However, collaboration is only a solution if one is prepared to shoulder the responsibility of developing interactional expertise, so as to understand in some depth the complementary knowledge of others (Collins 2007). Otherwise, collaborators notwithstanding, occupying a borderland can engender complacency about what it is necessary to know, with the risk of making claims that are in fact not sufficiently anchored in deep knowledge. Indeed collaboration can exacerbate the problem, unless there is sufficient openness and humility about areas of ignorance, and willingness to explain one's knowledge bases and assumptions to others in a way that they can fully understand and work with.

The informants in the study proposed effective and productive ways to navigate the challenges of working at the edge of one's theoretical and methodological 'comfort zone'. Firstly, the individuals we interviewed tended to acknowledge 
rather than deny a sense of standing on uneven ground. Secondly, they responded positively and creatively to the challenges of this uncertainty and the frequent encounter with others who had knowledge that they did not. For them, not knowing everything was a stimulus for new ideas, and they valued the new learning that happens at the cross-over points (Coupland, 1997:28). Having to explain their own knowledge to others was a way of developing a better understanding of their own area. Perhaps for this reason, they emphasised - to a greater extent overall than our non-linguist informants - the importance of good communication skills, collaboration and working in a high quality research environment.

Operating within this melting point of ideas offers applied linguists an important opportunity to generate new integrated theories of language in action. We have established above that many different theories can be applied to linguistic behaviour. Furthermore, language plays a role in most if not all of the great challenges of the modern world, from protecting the planet, to preventing or curing Alzheimer's disease; from combatting terrorism to harnessing technology. Language is, we might say, close to the heart of all research endeavour, whether as the object of study in literature or the means of interpretation and dissemination in hard sciences.

Applied linguistics occupies a unique place within the academic community, in that language is a phenomenon in its own right, with its own patterns of form and function; it is the substance of interaction; it is a window into thought and behaviour; and it is the primary medium of explication across all domains of research. As a result, applied linguistics sits in pole position to integrate claims about language from across many other disciplines - including linguistics - into more coherent and comprehensive accounts of how form, function and usage combine through learning and cognition to achieve social purposes, and how information across all domains of human activity are influenced the medium of their expression. Figure 3 superimposes onto Figure 2 the potential domain for integrated applied linguistic theory that could draw together the many disparate and often incompatible claims about language that arise from the contributing domains of research.

As Rampton (1997) points out,

Rather than simply borrowing theories from linguistics to try to solve languagerelated problems in the real world, applied linguistics ... should serve as a point of interdisciplinary synthesis where theories with their own integrity develop in close interaction with language users and professionals (p.3).

A particular potential strength of such synthesis is that applied linguistics is something of a Janus, on the one hand drawn to addressing social and cognitive questions and solving practical problems, and on the other rooted in description and 


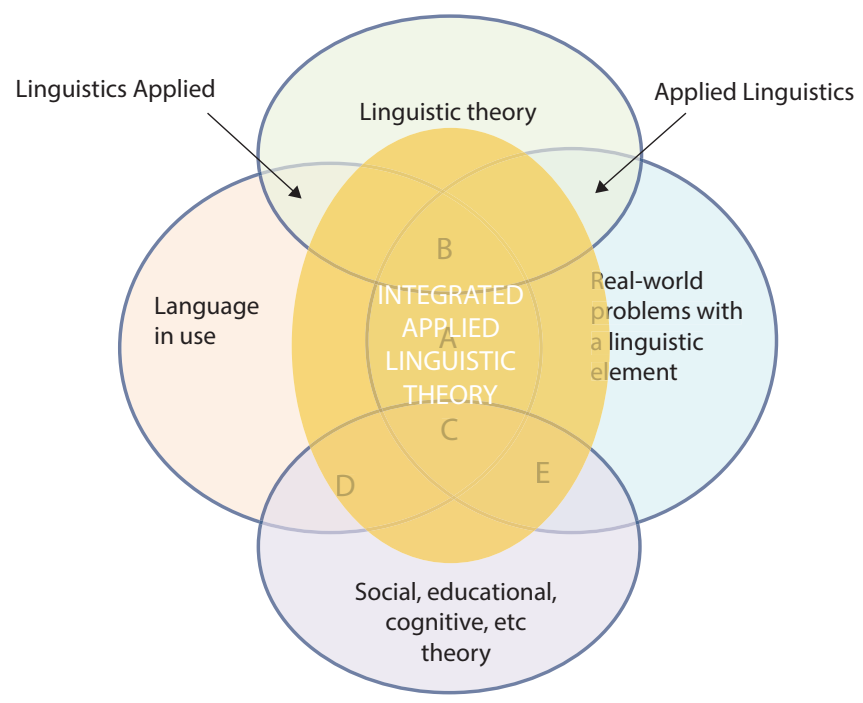

Figure 3. The scope for integrated applied linguistic theory

argument (see Rampton 1997, 6ff for discussion relevant to this observation). It sits at the meeting of the social, behavioural and learning sciences on the one hand, and the humanities on the other.

These are traditions that are driven by different purposes and legitimated in different ways. As a result, there is potential for applied linguistic theory to explore how inbuilt assumptions about the nature of knowledge impact on the claims that are made. It may find itself straddling the divides between positivism and relativism, narrative and controlled response, qualitative and quantitative data, nature versus nurture, and a range of familiar issues around normativity that include the status of non-nativisms, the continuum into 'abnormal' linguistic behaviour, definitions of comprehensibility, the reference points for standardisation and for artificial intelligence, and the representativeness of corpus evidence.

Given this position, applied linguists have the potential to play an important role within the interdisciplinary community, as expert integrators of the range of knowledge about language form, function, behaviour and cognitive provenance that the multi-disciplinary research community brings to the table. Applied linguists are familiar with the ambiguities of boundary-spanning investigation, and value the capacity to communicate effectively. They can show how the complex nature of language means it cannot be taken for granted, either as the object or medium of enquiry.

Bygate (2005) suggested a decade ago that applied linguistics had missed opportunities to deepen its engagement, and that it neither totally aligned with the needs of the potential users of its expertise, nor had entirely taken on the 
responsibility of full theoretical and methodological maturity. The comments of the informants in our study strongly suggest that core theoretical knowledge, and a mature approach to handling the boundaries of that knowledge, are vital to the continued development of expertise in applied linguistics for the future. The way to access the information required to make insightful observations at the interface is by creating and sustaining rich research environments, and by exercising openness to learning, awareness of the limitations of one's knowledge, and willingness to collaborate, and by developing the capacity to communicate one's ideas.

Applied linguistics has always been a domain in flux. By being responsive, attentive, eclectic and creative, the international community of applied linguists can reap great benefit from the new cross-disciplinary research agendas focussed on major practical humanitarian challenges. Language and communication are central to

- World-wide health objectives, from improving communication to assist the eradication of Ebola, AIDS and polio, to improving of the quality of life of older people through more satisfactory daily interaction

- International security, from understanding the persuasiveness of radicalisers, to critically examining how terms like 'torture' and 'extraordinary rendition' are deployed

- Universal literacy and education, from the protection and use of local languages, to new understandings of the cognitive and social barriers to reading

- Digital futures, from the collection and analysis of billion-word corpora, to the critical evaluation of linguistic phenotyping in preventative medicine

- Human rights, from understanding how being vocal does not necessarily give you voice, to improving the communicative effectiveness of legal documents.

Applied linguists already have the experience of working at interfaces that researchers in other disciplines must now develop. As such, and with a phenomenon as ubiquitous as language as their core concern, they are ideally placed to progress knowledge and contribute to tangible changes in practice across a wide range of socially relevant domains of investigation.

As Rampton (1997) observes, applied linguistics is "an open field of interest in language, in which... there is no knowing where, between whom, and on what the most productive discussions will emerge" (p. 14).

\section{References}

Agnew, N. M., Ford, K. M., \& Hayes, P. J. (1997). Expertise in context: Personally constructed, socially selected and reality-relevant? In P. J. Feltovitch, K. M. Ford, \& R. R. Hoffman (Eds.), 
Expertise in context: Human and machine (pp. 219-244). Menlo Park, CA/Cambridge, MA: AAAI Press/The MIT Press.

BAAL. (1997). Notes on the history of the British Association for Applied Linguistics 1967-1997. <http://www.baal.org.uk/dox/history_of_baal.pdf>

Bygate, M. (2005). Applied linguistics: A pragmatic discipline, a generic discipline? Applied Linguistics, 26(4), 568-581. DOI: 10.1093/applin/ami032

Chappelle, C. A. (2013). Introduction. In C. A. Chappelle (Ed.), The encyclopedia of applied linguistics (Vol.1; pp. lxvii-lxxv). Chichester: Wiley-Blackwell.

Chi, M. T. H. (2006). Two approaches to the study of experts' characteristics. In K. A. Ericsson, N. Charness, P. J. Feltovich, \& R. R. Hoffman (Eds.), The Cambridge handbook of expertise and expert performance (pp. 21-30). Cambridge: Cambridge University Press.

DOI: $10.1017 / \mathrm{CBO} 9780511816796.002$

Chi, M., Glaser, R., \& Rees, E. (1982). Expertise in problem-solving. In R. Stemberg (Ed.), Advances in the psychology of human intelligence (Vol. 1; pp. 7-75). Hillsdale, NJ: Lawrence Erlbaum Associates.

Collins, H. (2007). A new programme of research? Studies in the History and Philosophy of Science, 37, 615-620 DOI: 10.1016/j.shpsa.2007.09.004

Corder, S.P. (1973). Introducing applied linguistics. Harmondsworth: Penguin.

Coupland, N. (1997). Language, ageing and ageism: A project for applied linguistics? International Journal of Applied Linguistics, 7(1), 26-48.

DOI: 10.1111/j.1473-4192.1997.tb00102.x

Davies, A. (2007). An introduction to applied linguistics (2nd ed.). Edinburgh: Edinburgh University Press.

Davies, A., \& Elder, C. (Eds.). (2004). The handbook of applied linguistics. Oxford: Blackwell. DOI: $10.1002 / 9780470757000$

Donovan, A., Malone, M., Riestenberg, K., McGroarty, M., Tarone, E., \& Wiley, T. (2014). The state of applied linguistics: Past, present and future. Colloquium at American Association for Applied Linguistics Conference, Portland, OR, 25th March (pp. 159). <http://www.aaal. org/associations/12182/files/FINAL\%20AAAL\%202014\%20Conference\%20Progam\%20 for\%20Website.pdf>

Dreyfus, H., \& Dreyfus, S. (2005). Peripheral vision: Expertise in real world contexts. Organization Studies, 26(5), 779-792 DOI: 10.1177/0170840605053102

Ericsson, K. A. (2006a). The influence of experience and deliberate practice on the development of superior expert performance. In K. A. Ericsson, N. Charness, P. J. Feltovich, \& R. R. Hoffman (Eds.), The Cambridge handbook of expertise and expert performance (pp. 683703). Cambridge: Cambridge University Press. DOI: 10.1017/CBO9780511816796.038

Ericsson, K. A. (2006b). An introduction to Cambridge handbook of expertise and expert performance: Its development, organization, and content. In K. A. Ericsson, N. Charness, P. J. Feltovich, \& R. R. Hoffman (Eds.), The Cambridge handbook of expertise and expert performance (pp. 3-19). Cambridge: Cambridge University Press.

DOI: 10.1017/CBO9780511816796.001

Feltovich, P., Prietula, M., \& Ericsson, K. A. (2006). Studies of expertise from psychological perspectives. In K. A. Ericsson, N. Charness, P. J. Feltovich, \& R. R. Hoffman (Eds.), The Cambridge handbook of expertise and expert ferformance (pp. 41-67). Cambridge: Cambridge University Press. DOI: 10.1017/CBO9780511816796.004

Feltovich, P. J., Spiro, R. J., \& Coulson, R. L. (1997). Issues of expert flexibility in contexts characterized by complexity and change. In P. J. Feltovich, K. M. Ford, \& R. R. Hoffman (Eds.), 
Expertise in context: Human and machine (pp. 125-146). Menlo Park, CA/Cambridge, MA: AAAI Press/The MIT Press.

Hall, C. J., Smith, P. H., \& Wicaksono, R. (2011). Mapping applied linguistics. London: Routledge. Hoffman, R. R. (1998). How can expertise be defined? Implications of research from cognitive psychology. In R. Williams, W. Faulkner, \& J. Fleck (Eds.), Exploring expertise (pp. 81-100). Edinburgh: Edinburgh University Press.

House, J. (2009). Response in: What is applied linguistics? Cambridge University Press. <http:// www.cambridge.org/servlet/file/store7/item5633198/version1/Article_What\%20is\%20applied\%20linguistics.pdf>

Mieg, H. A. (2006). Social and sociological factors in the development of expertise. In K. A. Ericsson, N. Charness, P. J. Feltovich, \& R. R. Hoffman (Eds.), The Cambridge handbook of expertise and expert performance (pp. 743-760). Cambridge: Cambridge University Press. DOI: $10.1017 /$ CBO9780511816796.041

Rampton, B. (1997). 'Retuning in applied linguistics?' International Journal of Applied Linguistics, 7(1), 3-25. DOI: 10.1111/j.1473-4192.1997.tb00101.x

Ross, G. (2008). An interview with Harry Collins. American Scientist online. http://www.americanscientist.org/bookshelf/pub/an-interview-with-harry-collins>

Schraw, G. (2006) Knowledge: Structures and process. In P. Alexander \& P. Winne (Eds.), Handbook of educational psychology (2nd ed.), (pp. 245-263). Mahwah, NJ: Lawrence Erlbaum Associates.

Shanteau, J. (1988). Psychological characteristics and strategies of expert decision-makers. Acta Psychologica, 68, 203-215. DOI: 10.1016/0001-6918(88)90056-X

Sosniak, L. (2006). Retrospective interviews in the study of expertise and expert performance. In K. A. Ericsson, N. Charness, P. J. Feltovich, \& R. R. Hoffman (Eds.), The Cambridge handbook of expertise and expert performance (pp. 287-301). Cambridge: Cambridge University Press. DOI: 10.1017/CBO9780511816796.016

Widdowson, H. (2000). On the limitations of linguistics applied. Applied Linguistics, 21(1), 3-25 DOI: $10.1093 /$ applin/21.1.3

Wray, A., \& Wallace, M. (2011). Accelerating the development of expertise: A step-change in social science research capacity-building. British Journal of Educational Studies, 59(3), 241-264. Special issue Research capacity building in education. DOI: 10.1080/00071005.2011.599790

Wray, A., \& Wallace, M. (2014). Developing social science research expertise: A resource and guide for trainers. National Centre for Research Methods. <http://www.restore.ac.uk/researchexpertise/>

Wright, M. (2013) Homicide detectives' intuition. Journal of Investigative Psychology and Offender Profiling, 10, 182-199. DOI: 10.1002/jip.1383

\section{Appendix I: Interview questions}

1. The nature of research expertise in your discipline

a. How would you characterize different aspects of research expertise in [your discipline]?

b. Describe up to three examples of researchers whom you consider to be experts. In each case, what is it that you are seeing in them that marks them out as an expert researcher?

c. Insofar as you accept the description 'expert' in relation to yourself, what particular characteristics of an expert do you see in yourself? 
d. There's an increasing emphasis in social science research on collaboration between experts from different disciplinary backgrounds. Do you think that any specific characteristics are needed to be an expert at collaborating? Do they apply to you in your work?

2. The way in which you acquired your own research expertise

a. What's different about how you think about things in your research activity now compared to how you thought about them early on in your career? What have you learned along the way?

b. How did you learn the skills of an expert, particularly the thinking skills?

c. Are there any particular people who supported your learning, such as a mentor, or a role model? If so, how did they help you learn to become more expert in your research?

3. How you support others in developing research expertise

a. If you were advising someone about to embark on a large and complex project, what key advice would you give them regarding the likely pitfalls and ways of maximizing the chances of success?

b. Could you describe how you approach that part of your role which involves bringing on other researchers?

c. What advice would you give to the up-and-coming generation of researchers aspiring to become experts?

\section{Appendix 2: Literature review questions}

i. How is expertise defined and characterized generically?

ii. What sort of evidence underpins these definitions and characterizations?

A subsequent question was addressed through a critical analysis of the findings:

iii. To what extent is it possible and appropriate to apply the generic claims about expertise to the specific context of social science research expertise?

\section{Author's addresses}

Alison Wray

School of English,

Communication and Philosophy

Cardiff University

John Percival Building

Colum Drive

Cardiff CF10 3EU

UK

WrayA@cf.ac.uk
Mike Wallace

Cardiff Business School

Aberconway Building

Colum Drive

Cardiff, CF10 3EU

UK

WallaceAM@cf.ac.uk 